\title{
MEASUREMENT OF SURFACE TEMPERATURES
}

\author{
By Wm. F. Roeser and E. F. Mueller
}

ABSTRACT

After a brief discussion of some of the methods which have been used for measuring surface temperatures, the paper describes a surface thermometer of the thermocouple type which was successfully used for measuring the temperatures of steel rails during the periods of heating before and after welding. A compensated type of thermocouple, for more precise measurements at temperatures below $400^{\circ} \mathrm{F}$., is also described, and results obtained in measuring the temperature of a drying roll are given.

The measurement of the temperature of a surface, when this temperature differs considerably from that of the environment, offers difficulties not encountered in the usual kind of temperature measurements, and many special devices and refinements of technique have been applied in problems of this kind. In this note some of the available methods for measuring surface temperatures are described, with particular reference to two types of contact thermometers which were found to be serviceable in special cases.

The methods which are ordinarily used for measuring surface temperatures fall into four general classes: (1) Those in which substances which undergo visible alterations, such as color change or melting, at a fixed temperature, or within a narrow range of temperature, are placed on the surface; (2) those in which a thermometric device is permanently attached to the surface; (3) those in which the temperature of the surface is inferred from the indication of instruments actuated by the radiation emitted from the surface; and (4) those in which a thermometric device is placed on or near the surface and the temperature of the surface is inferred from the indications of the device.

It is well known that the melting, or still better, the freezing points of pure substances furnish one of the best means available for establishing thermometric fixed points. Under favorable circumstances such thermometric points have been found to be fixed and reproducible to $0.01^{\circ}$ or even to $0.001^{\circ} \mathrm{F}$. The favorable conditions are purity of material, usually most easily obtained in certain metals or simple inorganic compounds; adequate isolation and protection of the sample during the measurement, and insertion of the thermometer into the material. Under such conditions the accuracy attainable is limited principally by the purity of the material and the sensitivity and accuracy of the temperature-measuring device. Under less favorable conditions the accuracy may be much lower. If the material is impure or becomes contaminated during the measurement, melting or freezing will take place within a range of temperature which, in general, is below the melting point of the pure material.

If a pure material placed upon a heated surface is seen to melt, this gives positive assurance that the temperature of the surface is higher 
than the melting point of the material, provided only that there has been no contamination, in which case there is no definite melting point. If the material does not melt, this gives no positive assurance that the temperature of the surface is below the melting point of the material, because the piece placed on the surface is in thermal contact not only with the surface, but also with the surrounding medium, and therefore, assumes a temperature which is the resultant of all the influences to which it is subject. If molten material placed on a surface is seen to freeze, this can be taken to indicate that the temperature of the surface can not be much higher than the freezing point of the material. The method may, therefore, be capable of showing that the temperature of a surface is not below some known temperature, but does not yield other positive information.

The measurement of surface temperatures where the thermometric device is permanently attached is generally limited to the measurement of the temperature of stationary metal surfaces. This is commonly accomplished by drilling two small holes into the surface to a convenient depth and peening the bare end of each wire of a thermocouple into the separato holes. The ordinary welded junction is not employed, the circuit boing completed through the metal. If the wires are sufficiently small, the effect due to heat transfer along the wires is negligible. Even when the temperature of the surface is not uniform, the holes can usually be drilled so close together that the indication of the thermocouple will correspond approximately to the temperature of the surface immediately surrounding the place where the couple wires are peened. Several devices to bring the portion of the wires next to the junction to the same temperature as the junction, have been employed. One method which gives very satisfactory results is to run the thermocouple wires along the surface, so that the wires are in good thermal contact with the surface, but electrically insulated from it.

The measurement of the temperature of moving surfaces by thermometric devices which are permanently attached to the surface requires complicated auxiliaries, such as sliding electric contacts. This method is so complicated that it is not ordinarily employed.

Radiation and optical pyrometers whose indications depend upon the radiation received by the instruments are available for measuring surface temperatures. Theoretically the total radiation pyrometer can be used for measuring any temperature, but it is ordinarily not applied for temperatures below $1,200^{\circ} \mathrm{F}$. If the surface is exposed to view and above a red heat, the optical pyrometer may be employed and very satisfactory results obtained under favorable conditions.

The apparent temperatures indicated by these pyrometers are always lower than the true temperatures of the surfaces, by an amount depending upon the emission characteristics of the surfaces. Data are available for a large number of materials by means of which approximate corrections for emissivity may be made. The corrections in the case of the radiation pyrometer are much larger than in the case of the optical pyrometer, with a correspondingly larger uncertainty in the temperature found.

Contact thermometers have been made in a great variety of forms. Most of them contain a thermocouple which is so designed that when 
the thermometer is brought into contact with a surface, the junction of the thermocouple assumes nearly the temperature of the surface. If such a couple is first calibrated by contact with surfaces of known temperature, it can be used to measure the temperature of any similar surface.

In 1924 , at the request of the Joint Committee on Welded Rail Joints, American Bureau of Welding, there was designed and constructed at the National Bureau of Standards a contact pyrometer for determining the temperature of rails during the heating periods before and after the welding operation. This contact pyrometer shown in Figure 1 proved satisfactory for measuring the temperature of stationary metallic surfaces up to $1,300^{\circ}$ $\mathrm{F}$. The hot junction of this pyrometer consisted of a gold disk, $1 \mathrm{~mm}$ thick and $7 \mathrm{~mm}$ in diameter, into which two holes were drilled about $0.5 \mathrm{~mm}$ deep. No. 22 gage chromel and alumel thermocouple wires were hard soldered into these holes. The gold disk was backed with mica disks forming a stack 2 or 3 $\mathrm{mm}$ thick to provide thermal and electrical insulation between the hot junction and the supporting tube, as well as to cushion the gold disk. The front surface of the gold tip was made smooth to permit good thermal contact with the metallic surfaces.

It was found that when the gold disk was placed in firm contact with a hot metallic surface, the temperature of the disk was consistently lower than that of the surface by approximately 10 per cent of the difference between the air temperature and that of the hot surface. The instrument was calibrated by determining the emfs. when the disk was placed in contact with hot surfaces, the temperatures of

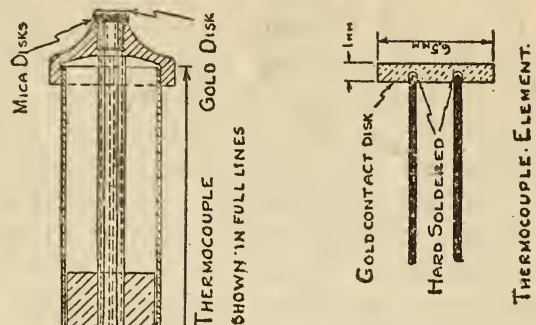
which were determined by means of thermocouples peened into the $11295^{\circ}-30-2$ 
metal. The time required to obtain a reading to an accuracy of $\pm 25^{\circ} \mathrm{F}$. at $1,100^{\circ} \mathrm{F}$. was approximately 30 seconds.

King and Blackie ${ }^{1}$ have described a thermocouple of this general type for measuring surface temperatures up to $200^{\circ} \mathrm{C}$. $\left(392^{\circ} \mathrm{F}\right.$.). The time required to obtain the surface temperature of a steel slab within $5^{\circ} \mathrm{C}$. $\left(9^{\circ} \mathrm{F}\right.$.) with this instrument was about six minutes. Neither of the above instruments is very satisfactory for obtaining the surface temperature of materials of very low thermal conductivity.

More recently another type of contact thermometer known as the compensated type has been introduced. One form of this instrument was described by Boyer and Buss. ${ }^{2}$ In the compensated type an electric heating coil is placed back of the measuring junction and the heating so regulated that the space back of the measuring thermojunction is brought to the same temperature as this junction. This equality is obtained by regulating the heating until the measuring junction and an auxiliary thermojunction placed between the
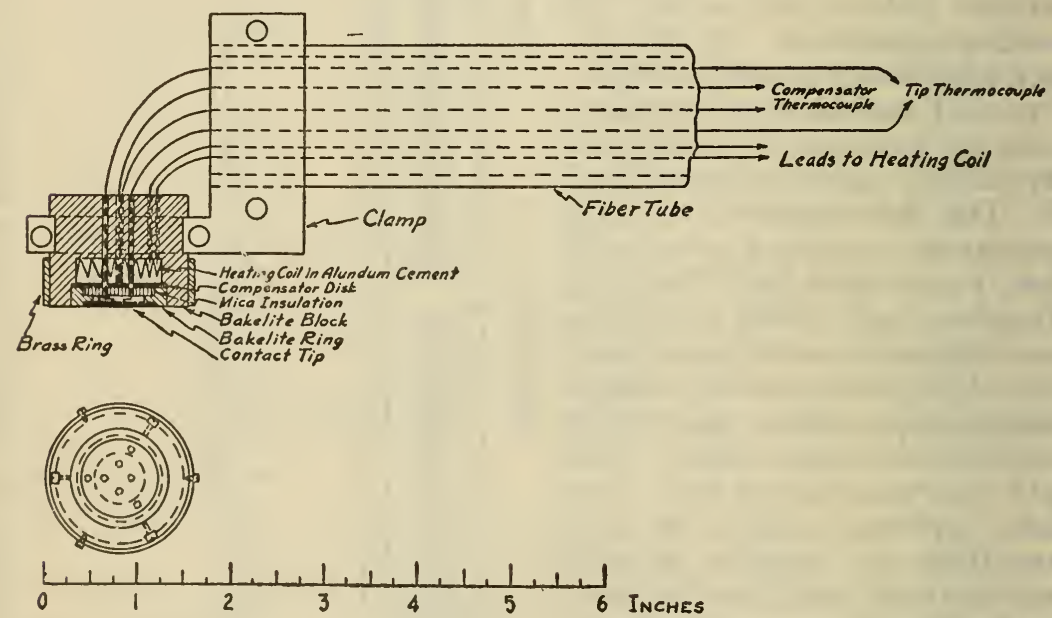

FIGURE 2.-Compensated contact thermometer for measuring surface temperatures up to $400^{\circ} \mathrm{F}$.

heating coil and measuring junction indicate the same temperature. Under these conditions no heat is conducted away from the measuring junction and the latter, therefore, assumes the temperature of the surface with which it is in contact. Such a contact thermometer need not be calibrated empirically under actual conditions of use, since the measuring junction necessarily assumes the temperature of the surface. Tests on heated surfaces of known temperature are desirable in order to verify the calibration and to determine the adequacy of the compensation.

An important advantage of the compensated thermometer over the simpler type first described lies in the fact that the indications are very little affected by thermal resistance between the surface and the junction, since there is no heat flow from the hot surface to the junction when readings are made. In fact, it should be possible to use a compensated couple to measure surface temperatures with 
considerable accuracy, while maintaining the junction at a small distance away from the heated surface instead of in contact with it.

A compensated contact thermometer is peculiarly adapted for measuring the temperature of a moving surface, when the temperature of the surface passing a given point in space is always the same, as is the case in most continuous processes. Such a thermometer is adapted primarily for measuring constant temperatures, since several minutes are required for the measuring couple to assume the temperature, and for adjusting the compensation and taking the readings.

In 1928 the authors designed and constructed a compensated contact thermometer for measuring the surface temperature of drying rolls in operation. A diagram of this instrument is shown in Figure 2 and the method employed for connecting the thermometer to the indicator is shown in Figure 3. The thermocouple elements are B. \& S. gage No. 22 chromel and alumel wire. The contact disk of the thermometer is made of "sumet," a bearing metal, having a

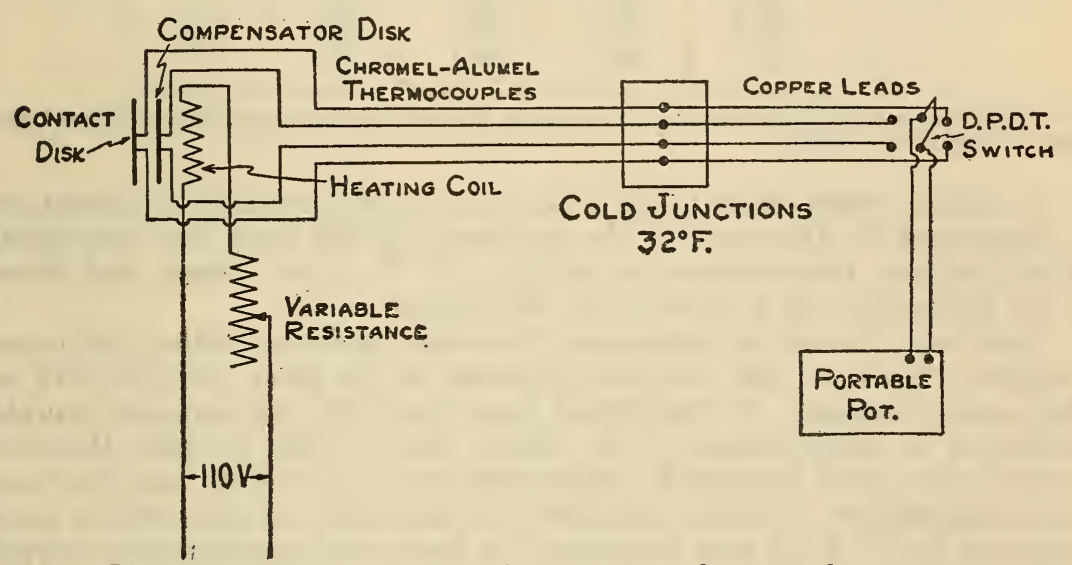

FIgURE 3.-Wiring diagram for compensated contact thermometer

low coefficient of friction against smooth steel or cast iron. This minimizes local heating of the contact tip by friction against the moving rolls. The "compensator" disk is made of copper in order to favor a uniform distribution of temperature back of the contact disk. Small holes were drilled into the disks and the thermocouple wires soldered into the holes with silver solder. The thermocouple wires of the contact disk were insulated from the compensator disk by small porcelain tubes.

The accuracy with which the temperature of a moving surface can be measured with such a contact thermometer remained to be determined. This was done by checking the thermometer on moving rolls inside of which known steam pressures were maintained.

The contact thermometer was first checked on paper drying rolls, the results being given in Table 1. A mercury-in-glass thermometer was placed in a thermometer well in the exhaust pipe from the roll on which the tests were made, and the observed temperatures were found to check with those calculated from these thermometer readings and from the steam pressure inside the roll. The particular roll 
on which the temperature measurements were made was partially protected from heat losses by other hot rolls below and on the sides. Under such conditions the drop in temperature through the metal wall of the roll was very low. It was estimated that the drop was $0.5^{\circ} \mathrm{F}$. and this amount has been subtracted from the steam temperature calculated from the pressure in order to obtain the true surface temperatures given in Table 1.

TABLE 1.-Checks on contact thermometer on paper drying rolls, 15-inch diameter

\begin{tabular}{|c|c|c|c|c|c|}
\hline $\begin{array}{l}\text { Surface } \\
\text { speed of } \\
\text { rolls }\end{array}$ & $\begin{array}{c}\text { Contact } \\
\text { thermometer } \\
\text { temperature }\end{array}$ & $\begin{array}{c}\text { Steam } \\
\text { temperature }\end{array}$ & $\begin{array}{l}\text { True sur- } \\
\text { face tem- } \\
\text { perature }\end{array}$ & $\begin{array}{l}\text { Thermome- } \\
\text { ter in well }\end{array}$ & Difference 1 \\
\hline $\begin{array}{c}F_{t} \text { min. } \\
\quad 47.5 \\
47.5 \\
47.5 \\
47.5 \\
58 \\
65\end{array}$ & $\begin{array}{l}{ }^{\circ} F . \\
250.5 \\
253.0 \\
261.0 \\
262.0 \\
268.5 \\
268.5 \\
265.0 \\
266.0 \\
266.5\end{array}$ & $\begin{array}{c}{ }^{\circ} F . \\
252.2 \\
252.5 \\
261.2 \\
261.2 \\
263.4 \\
269.1 \\
266.9 \\
266.0 \\
266.9\end{array}$ & $\begin{array}{c}{ }^{\circ} F . \\
251.7 \\
252.0 \\
260.7 \\
260.7 \\
267.9 \\
268.6 \\
266.4 \\
265.5 \\
266.4\end{array}$ & $\begin{array}{r}{ }^{\circ} F . \\
252.7 \\
252.7 \\
261.7 \\
261.7 \\
270.7 \\
264.0 \\
263.5 \\
265.0\end{array}$ & $\begin{array}{r}{ }^{\circ} F . \\
-1.2 \\
+1.0 \\
+.3 \\
+1.3 \\
+.6 \\
-.1 \\
-1.4 \\
+.5 \\
+.1\end{array}$ \\
\hline
\end{tabular}

1 This column gives the values of contact thermometer temperature (column 2) minus calculated (true) surface temperature (column 4).

It will be noted from Table 1 that the outside surface temperature as indicated by the contact thermometer agrees with the calculated (true) surface temperature to within $1.5^{\circ} \mathrm{F}$, in all cases, and there is no indication of a systematic difference.

Tests were made to determine the error produced when the compensator thermocouple was not adjusted to the same temperature as the contact couple. It was found that when the compensator couple indicated a temperature $5^{\circ} \mathrm{F}$. below that of the contact thermocouple, the latter indicated a termperature $1^{\circ} \mathrm{F}$. below the true surface temperature. Thus, to obtain an indication of the surface temperature to $1^{\circ} \mathrm{F}$. it was necessary to have the compensator couple indicate the same temperature as the contact couple to within $5^{\circ} \mathrm{F}$.

The contact thermometer was also checked on milk drying rolls running with known steam pressures with no milk on the rolls. The results of these tests are given in Table 2 . The rolls were protected from drafts and, in this case, it was estimated that the drop in temperature in the wall of the roll was $2^{\circ} \mathrm{F}$.

TABLE 2.-Checks on contact thermometer on milk drying rolls

[The diameter of the rolls was 28 inches. The surface speed of the rolls was 107 feet per minute]

\begin{tabular}{|c|c|c|c|}
\hline $\begin{array}{c}\text { Contact } \\
\text { thermometer } \\
\text { temperature }\end{array}$ & $\begin{array}{c}\text { Steam } \\
\text { temperature }\end{array}$ & $\begin{array}{c}\text { True sur- } \\
\text { face tem- } \\
\text { perature }\end{array}$ & Difference 1 \\
& ${ }^{\circ} F$. & ${ }^{\circ} F$. & ${ }^{\circ} F$. \\
${ }^{\circ} F$. & 264.5 & 262.5 & 0.0 \\
319.5 & 319.0 & 317.0 & +2.5 \\
317.0 & 317.4 & 315.4 & +1.6 \\
320.0 & 321.3 & 319.3 & +.7 \\
\hline
\end{tabular}

1 This column gives the values of contact thermometer temperature (column 1) minus the calculated (true) surface temperature (column 3). 


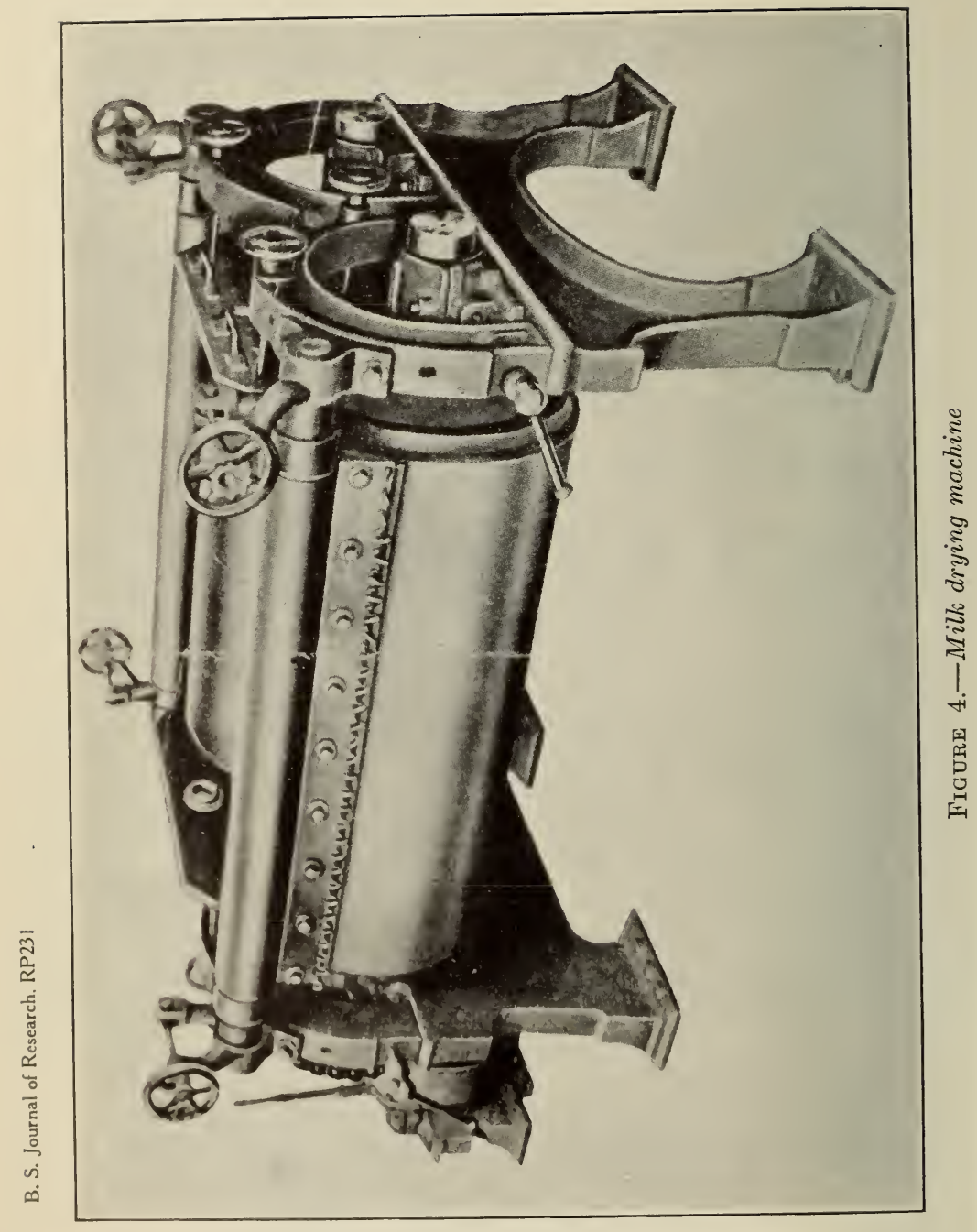


It will be noted from Table 2 that the outside surface temperature as indicated by the contact thermometer agrees with the calculated (true) surface temperature to within $2.5^{\circ} \mathrm{F}$. in all cases, while the average difference is $1.2^{\circ} \mathrm{F}$.

As an example of the application of this type of instrument to the measurement of surface temperature and of the magnitude of the temperature variations obtained in drying processes, the results of some measurements on the rolls of a milk drying machine while in operation will be given.

A photograph of a twin-cylinder machine is reproduced in Figure 4. The drying cylinders are made of cast iron and are heated from the inside by steam at a pressure of approximately $75 \mathrm{lbs}$./in. ${ }^{2}$ (gauge). The cylinders, 28 inches in diameter and 5 feet long, rotate about 14 times per minute. Fresh liquid milk is fed into the V-shaped space between the upper halves of the faces of the two cylinders and a fixed depth of liquid milk is maintained in that space during operation. A small quantity of the milk passes regularly between the cylinders (which are slightly separated from each other) and adheres in the form of a thin film upon the face of each cylinder, is dried thereon, and then removed by stripping knives held in contract with the rotating cylinders.

The temperature measurements on the rolls of the milk drying machines were made at a plant of the Dry Milk Co. For making measurements on the portion of the rolls carrying a milk film, an auxiliary knife was used for scraping the film from the roll. This knife scraped the milk off for a width of about 2 inches. It was placed at various points around the circumference at the middle of the roll and the contact thermometer was placed in a position about 2 inches behind the knife. Under these circumstances, while the rate of heat flow within the cylinder wall was not modified, the rate of heat loss from the portion of the surface at which measurements were being made was very nearly the same as the rate of heat loss from the surface of a clean, dry roll.

The values in Table 3 give the results of tests made on one of the rolls of one machine when operating at an average steam pressure of $64.2 \mathrm{lbs}$./in. ${ }^{2}$ (gauge). The position at which the contact thermometer was held are expressed as percentages of the circumference from the point of the rolls nearest to contact.

TABLF 3.-T'emperature measurements on milk drying rolls

[Steam pressure approximately $64 \mathrm{lbs} . /$ in. $^{2}$ (gauge). Corresponding steam temperature $311^{\circ} \mathrm{F}$.]

\begin{tabular}{|c|c|c|c|}
\hline 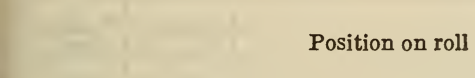 & Per cent & $\begin{array}{c}\text { Steam } \\
\text { pressure }\end{array}$ & $\begin{array}{l}\text { Surface } \\
\text { tempera- } \\
\text { ature }\end{array}$ \\
\hline $\begin{array}{l}\text { At top of roll } \\
6 \text { inches above knife } \\
31 / 4 \text { inches below knife } \\
1334 \text { inches below knife } \\
\text { At bottom of roll } \\
45^{\circ} \text { from bottom }\end{array}$ & $\begin{array}{l}75.0 \\
62.0 \\
51.0 \\
39.5 \\
25.0 \\
12.5\end{array}$ & $\begin{array}{r}\text { Lbs./in. }{ }^{2} \\
64.7 \\
65.2 \\
64.3 \\
64.7 \\
63.8 \\
62.5\end{array}$ & $\begin{array}{l}{ }^{\circ} F \text {. } \\
255.0 \\
251.0 \\
250.0 \\
244.5 \\
242.0 \\
238.0\end{array}$ \\
\hline
\end{tabular}

The values in Table 4 give the results of the tests on the same roll of the same machine when operating at an average steam pressure of $74.3 \mathrm{lbs} . /$ in. $^{2}$ (gauge). 
TABLE 4.-T'emperature measurements on milk drying rolls

[Steam pressure approximately $74 \mathrm{lbs} . / \mathrm{in.} .^{2}$ (gauge). Corresponding steam temperature $\left.319^{\circ} \mathrm{F}.\right]$

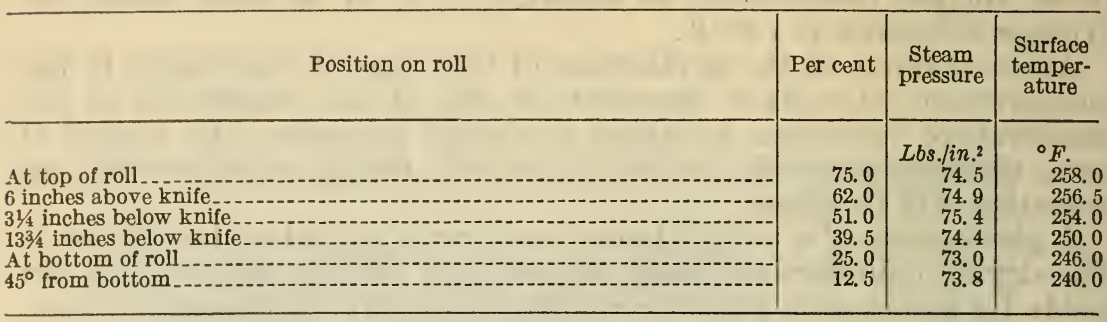

The observations given in Tables 3 and 4 are shown graphically in Figures 5 and 6 . Figure 5 indicates the cycle of temperature which a point on the roll goes through during each rotation.

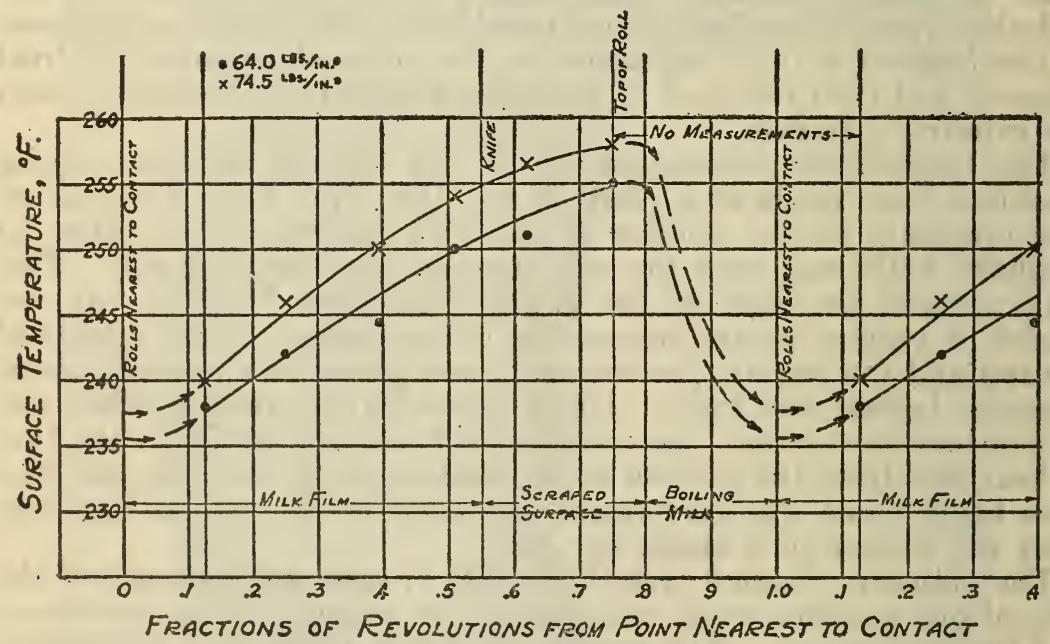

FigURE 5.-Cycle of temperaiure of a point on the surface of the roll

The following observations were taken at a point just below the knife on one of the rolls to determine the temperature drop in the milk film:

\begin{tabular}{|r|c}
$\begin{array}{c}\text { Steam } \\
\text { pressure }\end{array}$ & $\begin{array}{c}\text { Temper- } \\
\text { ature }\end{array}$ \\
\hline Lbs./in. ${ }^{2}$ & ${ }^{\circ} F$. \\
68.8 & 250.0 \\
71.7 & 218.0
\end{tabular}

At the point where these measurements made the milk film was practically free from moisture. Taking into consideration the change in steam pressure the temperature drop in the milk film was of the order of $3^{\circ} \mathrm{F}$. 
An attempt was made to determine the temperature of the upper surface of one of the rolls by applying fusible substances to the surface. Benzoic acid, pyrogallol, and a number of other substances were used.

In the experiments on the rolls of a paper drying machine very satisfactory results had been obtained on the clean, dry surfaces by applying a small bead of the material, inclosing the head of a pin, to the surface of the moving roll. When the temperature was below the melting point of the material, the bead made no mark on the roll but when the temperature was high enough to melt the material the bead left a wet streak on the roll.

When this method was applied to the milk drying machines under operating conditions it failed to yield definite results because the cylinders were not scraped entirely clean by the stripping knives

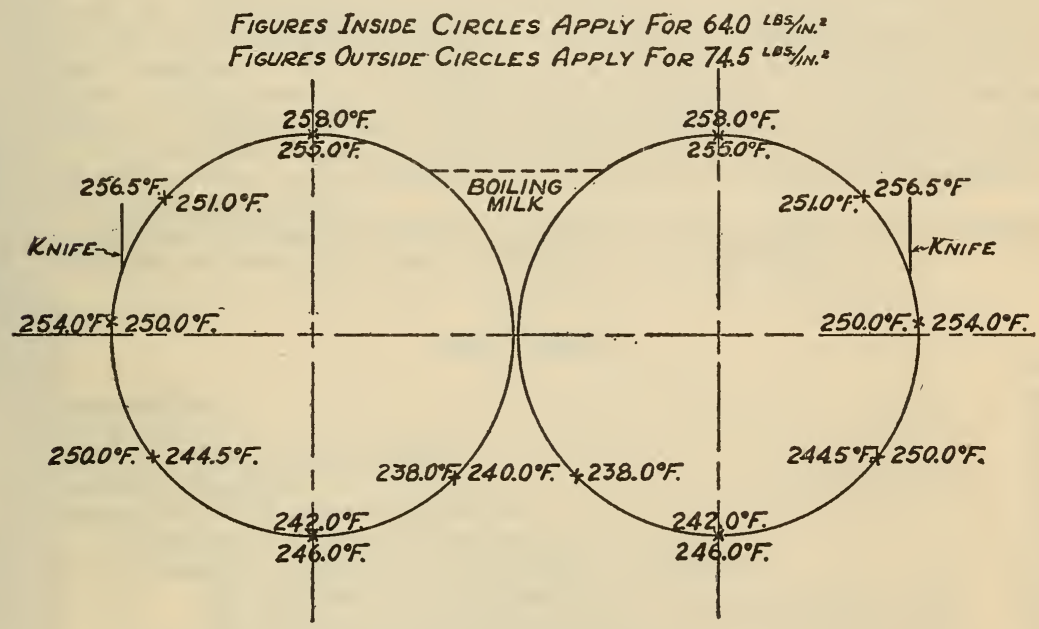

FIgURE 6.-Temperatures observed at various points on the rolls

The film of material on the cylinder was of such character that when the beads of various materials were held against the moving surface streaks always appeared. Streaks of practically the same appearance, however, were produced by beads of several fusible materials whose melting points, when pure, were known to be above the temperature of the roll. Even a piece of wood made a similar streak on the roll.

It was found that the rolls of the milk drying machine moved too rapidly to make the determination by placing small pieces of the fusible materials on the cylinder, since it was not possible, with the unaided eye, to observe whether melting took place or not. Stopping the machines long enough to make the observation would have involved a very uncertain extrapolation, since every accessible point on the surface was increasing in temperature by approximately $5^{\circ} \mathrm{F}$. per second. We thus have to record one more instance in which the measurement by means of fusible substances has failed to meet expectations. 


\section{SUMMARY}

Two types of contact thermometers are described in this paper, and the results of temperature measurements made on the rolls of paper and milk drying machines with one of the contact thermometers are also given. The surface temperatures of moving rolls have been determined to an accuracy of $2^{\circ} \mathrm{F}$. by means of a compensated contact thermometer.

Attempts to determine the approximate temperature of the surface of the moving rolls by employing fusible substances proved successful on clean, dry surfaces but were unsuccessful when applied to surfaces carrying foreign or contaminating materials.

Washington, June 9, 1930. 